\title{
Intrapulmonary protein leakage in immunocompromised children and adults with pneumonia
}

F Ratjen, W Havers, J Braun

\begin{abstract}
Background-Pulmonary infections are associated with an increase in capillary permeability but information regarding age related differences in the local inflammatory response is lacking. To quantify the degree of capillary leakage during inflammation, the concentrations of the plasma proteins albumin, $\alpha_{1}$-antitrypsin, $\alpha_{2}$-macroglobulin and the locally produced proteins elastase, myeloperoxidase, lactoferrin and fibronectin were studied in the bronchoalveolar lavage (BAL) fluid of immunosuppressed children and adults with pneumonia.
\end{abstract}

Methods-Sixteen children aged 2-16 years and 15 adults who developed pneumonia while receiving immunosuppressive therapy for haematological malignancies were included in the study. Bronchoalveolar lavage was performed via a flexible bronchoscope with three aliquots of $1 \mathrm{ml} / \mathrm{kg}$ body weight in children and $200 \mathrm{ml}$ in adults. Protein concentrations in BAL fluid were determined using highly sensitive immunoluminometric assays.

Results-Despite considerable variability, the median concentrations of all proteins in BAL fluid were significantly higher in both patient populations than in previously collected age adjusted reference values. The concentrations of serum derived proteins were significantly higher in children with pneumonia than in adult patients. In contrast, no differences were observed between the two groups for locally produced proteins.

Conclusions-These data suggest that the degree of protein exudation is more pronounced in immunosuppressed children with pneumonia than in adults in a similar clinical situation. This is in agreement with our studies in healthy individuals and may reflect a greater permeability of the alveolar-capillary membrane in children, regardless of disease status.

(Thorax 1999;54:432-436)

Keywords: bronchoalveolar lavage; immunocompromised children; pneumonia; protein leakage

Pneumonia is a frequent complication in immunocompromised patients and causes significant morbidity and mortality. ${ }^{1}$ While the spectrum of organisms causing pulmonary infection has been well described both in chil- dren and in adults, ${ }^{2-6}$ there is little information on the pathophysiological changes induced by the inflammatory process, especially in children.

The presence of pathogens leads to an influx of neutrophils and/or lymphocytes in the lung, which is demonstrable by bronchoalveolar lavage (BAL) in most patients. ${ }^{7}$ Neutrophils release proteins such as elastase and myeloperoxidase that may be harmful to the lung and increase the inflammatory reaction. The inflammatory response and immunosuppression alter capillary permeability and favour an influx of plasma proteins into the alveolar space. The accumulation of these osmotic substances may result in pulmonary oedema by solvent drag and may further impair diffusion of oxygen through the alveolo-capillary membrane, ultimately leading to respiratory failure. We have previously found higher concentrations of plasma derived proteins in children without lung disease compared with healthy adults, whereas locally produced proteins did not differ between the two groups. ${ }^{8}$ This would suggest that the permeability of the alveolocapillary membrane may be higher in children. To quantify the degree of capillary leakage during pulmonary inflammation we have therefore studied plasma proteins as well as locally produced proteins in the BAL fluid of immunosuppressed children and adults with pneumonia.

\section{Methods}

Sixteen children of mean (SD) age 8.2 (5.3) years (range 2-16) and 14 consecutive adult patients of mean (SD) age 54 (12) years with haematological malignancies and pneumonia were included in this study. The clinical diagnoses of the study population are shown in table 1. All patients had received immunosuppressive chemotherapy before they developed pneumonia. The children were all treated prophylactically with cotrimoxazole for Pneumocystis carinii infection before the onset of their pulmonary illness and broad spectrum antibiotic therapy at the time of BAL. Seven children were also treated with amphotericin B. Eight of the children had developed respiratory failure with the clinical presentation of ARDS. All adults received prophylactic treatment with ciprofloxacin, but no additional antibiotic or antifungal therapy prior to BAL. All the patients were febrile and had clinical signs of pneumonia. Chest radiographs in both patient populations varied from local infiltrates to diffuse interstitial changes. 
Table 1 Underlying diagnoses of the study population

\begin{tabular}{lll}
\hline & Children & Adults \\
\hline Acute lymphoblastic leukaemia & 7 & \\
Acute myeloid leukaemia & 5 & \\
Chronic lymphoblastic leukaemia & 1 & \multirow{2}{*}{10} \\
Non-Hodgkin's lymphoma & 1 & \\
Medulloblastoma & 1 & \\
Rhabdomyosarcoma & 1 & 3 \\
Chronic myeloid leukaemia & & 1 \\
Hodgkin's disease & & \\
\hline
\end{tabular}

Table 2 Microbiology of BAL fluid in immunosuppressed children and adults with pneumonia

\begin{tabular}{lcl}
\hline Organism & Children & Adults \\
\hline Aspergillus fumigatus & 3 & 1 \\
Pneumococcus & 1 & 1 \\
Pneumocystis carinii & 1 & 4 \\
Pseudomonas aeruginosa & & 1 \\
Haemophilus influenzae & & 1 \\
Staphylococcus epidermidis & 11 & 2 \\
No microorganism identified & & 4 \\
\hline
\end{tabular}

The group of children without respiratory diseases has been described in detail previously. ${ }^{9}$ Briefly, all children were undergoing elective surgery for non-respiratory illnesses and were free of respiratory symptoms at the time of the procedure. Informed consent from both parents was obtained in all cases. BAL was performed immediately after the onset of general anaesthesia in all children without respiratory disease as well as in immunosuppressed children with pneumonia as described previously. ${ }^{9}$ Children with respiratory failure who were mechanically ventilated received midazolam $0.1-0.3 \mathrm{mg} / \mathrm{kg}$ body weight for the bronchoscopic procedure.

A flexible bronchoscope (Pentax 3.5 or 4.9 $\mathrm{mm}$, Hamburg, Germany) was introduced through an adapter attached to the endotracheal tube, thereby maintaining mechanical ventilation. The bronchoscope was wedged in the area of maximal disease as suggested by the radiograph or in the middle lobe in patients with diffuse interstitial changes. BAL was performed in the lateral segment of the middle lobe or the lingula in 10 patients, in the upper lobes in three, and in the lower lobes in three patients. Three aliquots of normal saline $1 \mathrm{ml} /$ $\mathrm{kg}$ body weight warmed to body temperature $\left(37^{\circ} \mathrm{C}\right)$ were instilled and immediately withdrawn. In children weighing more than $20 \mathrm{~kg}$, $20 \mathrm{ml}$ portions were instilled up to a total volume of $3 \mathrm{ml} / \mathrm{kg}$ body weight. The first sample was used for bacterial and fungal studies only; subsequent samples were pooled for analysis. Both samples were stained by the Gram, ZiehlNeelsen, and potassium hydroxide methods. In addition, bacterial, fungal and viral cultures as well as silver stains for Pneumocystis carinii were performed on the pooled BAL fluid samples.

Table 3 Median (range) laboratory data for both patient populations

\begin{tabular}{llll}
\hline & Children & Adults & $\begin{array}{l}\text { pvalue } \\
\text { (Wilcoxon test) }\end{array}$ \\
\hline Blood neutrophils/ $\mu \mathrm{l}\left(\times 10^{3}\right)$ & $1.4(0-42.9)$ & $1.85(0.12-7.9)$ & 0.56 \\
Serum CRP $(\mathrm{mg} / \mathrm{l})$ & $65(0.5-480)$ & $39.5(0.5-133)$ & 0.18 \\
BAL macrophages $(\%)$ & $45(2-97)$ & $40(1-98)$ & 0.89 \\
BAL lymphocytes $(\%)$ & $14.5(3-98)$ & $4.8(0-95)$ & 0.022 \\
BAL neutrophils $(\%)$ & $6(0-79)$ & $10(0-95)$ & 0.27 \\
\hline
\end{tabular}

$\mathrm{CRP}=\mathrm{C}$ reactive protein $; \mathrm{BAL}=$ bronchoalveolar lavage.
The adult reference population consisted of 16 healthy male volunteers aged $20-28$ years. $^{8}$ BAL was performed under local anaesthesia with 2\% lignocaine (lidocaine) and sedation with $2.5-7.5 \mathrm{mg}$ midazolam through a flexible bronchoscope (Olympus IT 20). $200 \mathrm{ml}$ of sterile isotonic saline was instilled in $20 \mathrm{ml}$ syringes and manually withdrawn. The site of BAL in patients with pneumonia was the lateral segment of the middle lobe or lingula in seven, the lower lobe in five, and the upper lobes in three patients, whereas the lateral segment of the right middle lobe was used in all healthy subjects. As with the studies in children, the first sample was considered a primarily bronchial sample and was treated separately; subsequent samples were pooled for analysis. Measurements of proteins in BAL fluid were performed on the pooled samples only.

BAL fluid was filtered through sterile gauze and centrifuged at $500 \mathrm{~g}$ for 10 minutes. The supernatant was separated and stored at $-20^{\circ} \mathrm{C}$ prior to analysis. Bronchoalveolar differential cell counts were obtained from smears stained with May-Grünwald-Giemsa. At least 600 cells were counted in each subject. The plasma proteins albumin, $\alpha_{1}$-antitrypsin, and $\alpha_{2}-$ macroglobulin, as well as the locally produced proteins elastase, myeloperoxidase, lactoferrin and fibronectin were determined in the supernatant of BAL fluid after separation of the cells using immunoluminometric assays as previously described. ${ }^{9}$ All assays were validated by adding known quantities of proteins to BAL fluid.

$\mathrm{C}$ reactive protein (CRP) as a marker of inflammation was determined from serum samples by immunonephelometry (Beckmann, Munich, Germany).

\section{STATISTICAL ANALYSIS}

All data were tested for normal distribution with the Kolmogorov-Smirnov test. Because of the non-parametric distribution of BAL proteins, results were expressed as median and ranges. Differences between the two patient populations were assessed with the WilcoxonMann-Whitney U test. A $p$ value of $<0.05$ was considered significant.

\section{Results}

Bronchoalveolar lavage was well tolerated in all patients. No complications occurred that could be related to the procedure except for an increased cough in the first hours following it that subsided after administration of a single dose of codeine. Infectious organisms were detected in the BAL fluid of five children and 10 adults (table 2). In one child the BAL fluid was sterile but Paecilomyces variotii, a fungus with similarities to Aspergillus, was cultured from a transbronchial biopsy specimen.

Laboratory findings and cytological results of BAL fluid in both patient groups are shown in table 3. There were no significant differences between the two groups in blood neutrophil counts and CRP levels, although the highest values were observed in the paediatric population. There was a wide variation in the 
Table 4 Median (range) protein concentrations in BAL fluid

\begin{tabular}{|c|c|c|c|c|}
\hline & $\begin{array}{l}\text { Normal children }(n= \\
\text { 39) }\end{array}$ & $\begin{array}{l}\text { Children with pneumonia } \\
(n=16)\end{array}$ & $\begin{array}{l}\text { Normal adults ( } n= \\
\text { 16) }\end{array}$ & $\begin{array}{l}\text { Adults with pneumonia } \\
(n=15)\end{array}$ \\
\hline Albumin (mg/l) & $16(0.5-70)$ & $175(8.8-1867)$ & $9.7(3.8-24)$ & $53(2.6-119)^{\star}$ \\
\hline$\alpha_{1}$-antitrypsin $(\mathrm{mg} / \mathrm{l})$ & $1.05(0.03-5.7)$ & $29(2.7-269)$ & $0.18(0.01-0.98)$ & $5.3(0.2-53)^{\star}$ \\
\hline$\alpha_{2}$-macroglobulin $(\mathrm{mg} / \mathrm{l})$ & $0.15(0-3.8)$ & $10.2(0.2-134)$ & $0+$ & $1.1(0.01-21)^{\star}$ \\
\hline Myeloperoxidase $(\mathrm{mg} / \mathrm{l})$ & $0(0-161)$ & $782(106-13000)$ & $23.5(1-51)$ & $781(9-14100)$ \\
\hline Elastase (mg/l) & $0(0-21)$ & $36(7-1340)$ & $2.1(1-14)$ & $71(0.1-3190)$ \\
\hline Lactoferrin $(\mathrm{mg} / \mathrm{l})$ & $27(2.1-288)$ & $617(82-5328)$ & $31(10-84)$ & $652(8-2946)$ \\
\hline Fibronectin (mg/l) & $0.1(0.01-0.37)$ & $1.33(0.23-11)$ & $0.08(0.02-0.2)$ & $0.72(0.08-8.2)$ \\
\hline
\end{tabular}

$\star$ Significantly different from children with pneumonia.

$+\alpha_{2}$-macroglobulin was undetectable $(<0.01 \mathrm{mg} / \mathrm{l})$ in all normal adults.

cytological findings of BAL fluid in both children and adults (table 3 ).

Serum derived proteins in the BAL fluid of the immunosuppressed children with pneumonia compared with reference values are shown in table 4. Despite considerable variability in all proteins, the median concentrations of albumin, $\alpha_{2}$-macroglobulin and $\alpha_{1}$-antitrypsin were significantly higher in both patient populations than the reference values (table 4, figs 1 and 2). The concentrations of serum derived proteins were significantly higher in children with pneu-

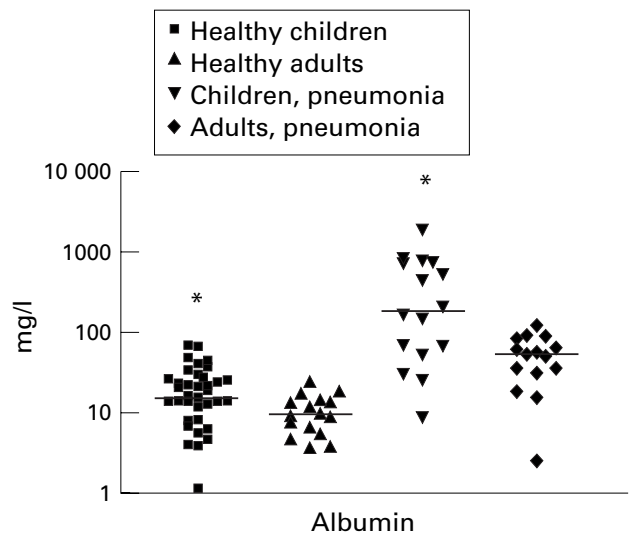

Figure 1 Concentrations of albumin in BAL fluid of immunosuppressed children and adults with pneumonia compared with reference values. Each symbol represents one individual. A logarithmic scale was used for the $y$ axis. The line represents the median value. Significantly higher concentrations were observed in children than in adults, as was observed in healthy subjects.



Figure 2 Concentrations of $a_{2}$-macroglobulin in $B A L$ fluid of immunosuppressed children and adults with pneumonia compared with reference values. Each symbol represents one individual. A logarithmic scale was used for the $y$ axis. The line represents the median value. Significantly higher concentrations were observed in both healthy children and immunosuppressed children with pneumonia than in adults. Note that $\alpha_{2}$-macroglobulin is not found in BAL fluid of healthy adults. monia than in the adult patient population (table 4, figs 1 and 2). These differences were observed for all serum derived proteins independent of their individual size (figs 1 and 2). There were no differences in serum derived protein levels between those children with bacteria or fungi in the BAL fluid and those in whom no pathogen could be detected (data not shown). In addition, no differences were observed between those on mechanical ventilation who had clinical signs of ARDS and those breathing spontaneously. There was a loose, albeit significant, correlation between the serum levels of CRP, reflecting the degree of systemic inflammation,

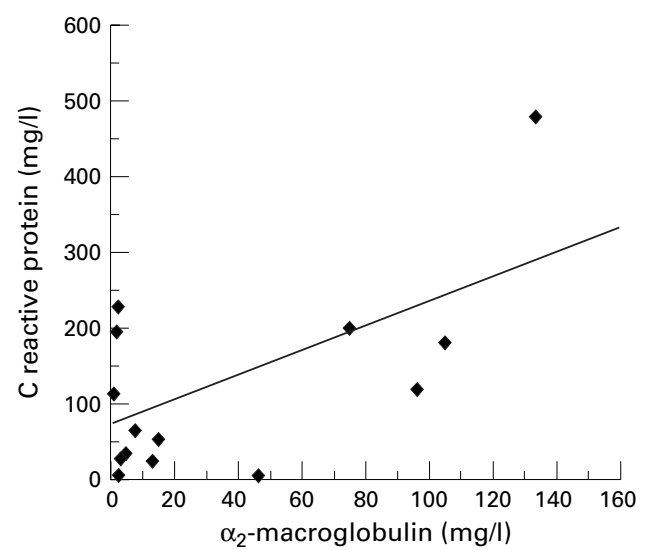

Figure 3 Correlation between concentrations of $a_{2}$-macroglobulin in BAL fluid and C reactive protein in serum of immunosuppressed children with pneumonia. Each symbol represents one individual. Levels of $a_{2}$-macroglobulin were significantly increased with increasing levels of $C$ reactive protein $(r=0.61, p=0.012$, linear regression analysis).

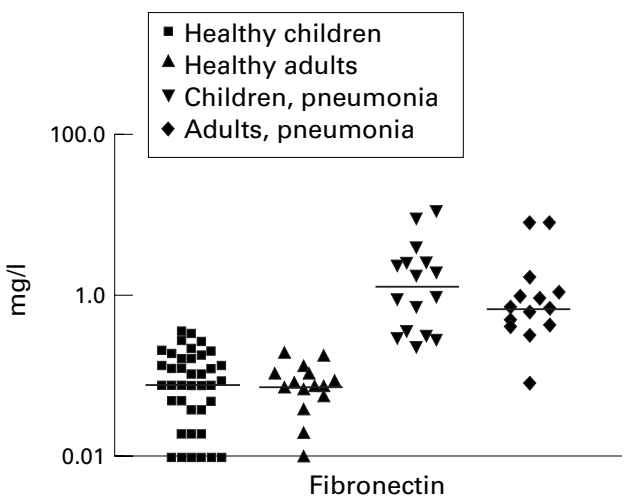

Figure 4 Concentrations of fibronectin in BAL fluid of immunosuppressed children and adults with pneumonia compared with reference values. Each symbol represents one individual. A logarithmic scale was used for the y axis. The line represents the median value. While higher

concentrations were observed in both immunosuppressed children and adults with pneumonia, no differences were observed between the two patient populations. 
and $\alpha_{2}$-macroglobulin concentrations in BAL fluid in children, suggesting that those with more intense systemic inflammation had a higher degree of protein leakage into the alveolar compartment (fig 3).

The concentrations of fibronectin in BAL fluid, as a representative example of locally produced proteins, are shown in fig 4 . As with proteins derived from the systemic circulation, there was a significant increase in locally produced proteins in both patient populations (table 4). No significant differences were observed between children and adults for locally produced proteins (table 4, fig 4).

\section{Discussion}

Our results show that leakage of plasma proteins is a common feature in immunosuppressed children with pneumonia and appears not to be related to the type of infection or clinical status of the patient. The degree of protein exudation is, however, more pronounced in children than in adults in a similar clinical situation. This is in agreement with our studies in normal children in whom we found approximately twice the concentration of serum derived proteins in the BAL fluid compared with healthy adults.

Several studies have used protein concentrations in BAL fluid as a marker of capillary leakage in lung diseases such as sarcoidosis and idiopathic pulmonary fibrosis. ${ }^{11}{ }^{12}$ Despite the high incidence of pneumonia in medically immunosuppressed patients and its high mortality, there have been no studies of the integrity of the alveolo-capillary membrane in subjects with this disease. This may be due to the fact that the conventional assessment of a capillary leak was performed using radioactive labelled albumin. In contrast to this method, the quantification of macromolecules in BAL fluid is much more feasible, especially in studies in children.

The higher protein concentrations in BAL fluid of children could be due to both technical and physiological differences. The larger dead space of the adult bronchoscope can be expected to result in a greater dilution of BAL fluid constituents as a smaller volume reaches the respiratory system. While differences in dilution may cause higher concentrations of proteins in the BAL fluid of children, this would not explain why only the concentrations of plasma proteins and not of locally released proteins were increased.

The smaller working channel of the paediatric bronchoscope will result in a higher aspiration pressure in children in order to recover the instilled fluid. Although we have not measured the aspiration pressure, Riedler et al have monitored suction pressure during BAL in children and found it to be twice as high as in adults. ${ }^{13}$ This could result in more proteins being drawn into the lung during the lavage procedure. Studies in humans have, however, shown that the time constant for larger sized molecules such as albumin and $\alpha_{2}$ macroglobulin is rather long. ${ }^{14}{ }^{15}$ Although this may change due to the disease state, these data make it unlikely that diffusion during the lavage process alone causes the observed differences between children and adults that were seen in both healthy individuals and subjects with lung disease.

In addition to the technical explanations, physiological differences between children and adults have to be considered. It would appear that children display a greater permeability of the alveolar-capillary membrane in both health and disease. The presence in the BAL fluid of normal children of $\alpha_{2}$-macroglobulin, a large molecule $(720 \mathrm{kDa})$ which was absent in all healthy adults, would suggest that this increase in permeability is not selective. This may be important for the pathophysiology of pneumonia in immunocompromised children as a greater permeability would favour pulmonary oedema, thereby impairing gas exchange due to an increased diffusion distance. ${ }^{16}$

In this study we found a high variability of all proteins in the BAL fluid which may reflect the problems of quantification of substances in BAL fluid when there is no reliable denominator. ${ }^{17}$ As there is currently no reliable method available to quantify the epithelial lining fluid, we have elected not to "normalise" our data by means of other BAL constituents. As is apparent from table 3, all plasma proteins as well as the locally produced proteins were increased during pulmonary inflammation compared with the reference populations which would indicate that the changes are non-selective as well as non-specific, at least for the proteins included in this analysis.

Leakage of plasma proteins into the lung appears to play a role in the pathogenesis of ARDS as these proteins can inactivate surfactant. ${ }^{18} 19$ In our population we did not observe higher levels of plasma proteins in those children with ARDS. None of the other children developed ARDS or respiratory failure later in the course of their illness. The measurement of protein concentrations in the BAL fluid does not therefore appear to be a useful marker for the development of ARDS in immunocompromised children with pneumonia.

1 Williams DM, Remington JS. Pulmonary infection in the immunocompromised host. Am Rev Respir Dis 1976;114:259-64.

2 Pizzo PA. Management of fever in patients with cancer and treatment induced neutropenia. N Engl F Med 1993;328: 1323-32.

3 De Blic J, McKelvie P, Le Bourgois M, et al. Value of bronchoalveolar lavage in the management of severe acute pneumonia and interstitial pneumonitis in the immunocompromised child. Thorax 1987;42:759-65.

4 Frankel LR, Smith DW, Lewiston NJ. Bronchoalveolar lavage for the diagnosis of pneumonia in the immunocompromised child. Pediatrics 1988;81:785-8.

5 Stokes DC, Shenep JL, Parham D, et al. Role of flexible bronchoscopy in the diagnosis of pulmonary infiltrates in bronchoscopy in the diagnosis of pulmonary infiltrates in

pediatric patients with cancer. F Pediatr 1989;115:561-7.
6 Winthrop AL, Waddell T, Superina RA. The diagnosis of pneumonia in the immunocompromised child: use of bronchoalveolar lavage. F Pediatr Surg 1990;25:878-80

7 Ratjen F, Havers W, Costabel U. Differential cytology of bronchoalveolar lavage fluid in immunosuppressed children with pulmonary infiltrates. Arch Dis Child 1996;74: $507-11$.

8 Braun J, Mehnert A, Dalhoff K, et al. Different BALF protein composition in normal children and adults. Respiration 1997;64:350-7.

9 Ratjen F, Bredendiek M, Brendel M, et al. Differential cytology of bronchoalveolar lavage fluid in normal children. Eur Respir 7 1994; 7:1865-70.

10 Braun J, Schultek T, Tegtmeier KF, et al. Luminometric assays of seven acute-phase proteins in minimal volumes of serum, plasma, sputum, and bronchoalveolar lavage. Clin Chem 1986;32:743-7.

11 Spatafora M, Mirabella A, Rossi GA, et al. Lung inflammation in sarcoidosis: analysis of immunglobulin levels in 
bronchoalveolar lavage fluid in active and inactive disease. Respiration 1985;48:127-35.

12 Vandenplas $\mathrm{O}$, Depelchin S, Delaunois L et al. Bronchoalveolar lavage $A$ and $G$ and antiproteinase correlate with changes in diffusion indices during the natural course of pulmonary sarcoidosis. Eur Respir F 1994;7:1856-64.

13 Riedler J, Grigg J, Stone CH, et al. Bronchoalveolar lavage in healthy children. Am f Respir Crit Care Med 1995;152:1638.

14 Normand ICS, Olver RE, Reynolds EOR, et al. Permeability of the lung capillaries and alveoli to non-electrolytes in the foetal lung. F Physiol 1971;219:303-30.

15 Hastings RH, Grady M, Sakuma T, et al. Clearance of different-sized protein from the alveolar space in humans and rabbits. F Appl Physiol 1992;73:1310-6.
16 Brigham KL. Lung edema due to increased vascular permeability. In Staub NC, ed. Lung water and solute exchange. Lung Biology in Health and Disease Series, Volume 7. New York: Marcel Dekker, 1978:65-73.

17 Von Wichert P, Joseph K, Mueller B, et al. Bronchoalveolar lavage. Quantification of intra-alveolar fluid? Am Rev Respir Dis 1993;147:148-52.

18 Holter JF, Weiland JE, Pacht ER, et al. Protein permeability in the adult respiratory distress syndrome. $\mathcal{f}$ Clin Invest 1996;78:1513-22.

19 Pittet JF, Mackersie RC, Martin TR, et al. Biological markers of acute lung injury: prognostic and pathogenetic significance. Am f Respir Crit Care Med 1997;155:1187205. 